\title{
Affective Incorporation
}

\author{
Giovanna Colombetti \\ Department of Sociology, Philosophy, and Anthropology \\ University of Exeter
}

\section{Introduction}

Classic and more recent phenomenological works provide rich accounts of our experience of the body and of its relation to the world. ${ }^{1}$ In this chapter I pull out one thread from this literature, focusing on the phenomenon of incorporation: literally, the capacity of the body to take something else into itself. As we will see, to date this phenomenon has been discussed primarily, if not exclusively, in relation to our sensorimotor capacities. The aim of this chapter is to show that not just the sensorimotor body (the perceiving and moving body) but the affective body too is subject to the process of incorporation.

To show this, I proceed as follows. In section 2 I introduce the phenomenon of incorporation, as described in particular in Merleau-Ponty and more recently Ihde. ${ }^{2}$ As I point out, Merleau-Ponty appears to use the term in two closely related but different ways: to refer, generally, to the acquisition of a variety of habitual bodily skills; and, more specifically, to refer to the integration of material objects into habitual bodily skills. To distinguish between these two senses of incorporation, I call the first phenomenon habit-incorporation and the second object-incorporation. In section 2 I also briefly refer to Ihde's Technics and Praxis to characterize object-incorporation in more detail, and to introduce some terminology and notation that will be useful in the subsequent discussion. After these introductory 
Forthcoming in J.E. Hackett \& J.A. Simmons (Eds.) (2016), Phenomenology for the Twenty-First Century. Palgrave Macmillan.

considerations, I turn to affectivity and show how the notion of incorporation, in both its general and specific sense, applies to affective states. In section 3 I discuss the case of affective habit-incorporation. I do so rather swiftly because, as I point out, this phenomenon is ubiquitous and not particularly difficult to identify. The case of affective object-incorporation (the integration of material objects into the affective body), on the other hand, is less obvious and more challenging to characterize and recognize. In section 4 I argue that this phenomenon however does exist, and provide two examples to illustrate it. In this way, we will see that a classical debate can be renewed and invigorated today such that new spaces might open up for the future of phenomenological research into affectivity and embodiment.

\section{Incorporation into the Sensorimotor Body}

In Phenomenology of Perception, Merleau-Ponty describes the phenomenon of incorporation as part of his discussion of the body schema (schéma corporel) ${ }^{3}$ and the habitual body. The notion of the body schema refers to the body experienced not as an object but as a subject of awareness; the body schema, in other words, is the lived body, i.e., one's own body experienced from the first-person perspective. While not itself an object of awareness, the lived body is the condition of possibility for our experience of objects in the world. ${ }^{4}$ As Merleau-Ponty puts it, the body schema is the 'zone of non-being in front of which precise beings, features, and points can appear. ${ }^{, 5}$ Because the body schema cannot be observed, it is also said to be 'non-thematic' or 'non-positional.'

Merleau-Ponty emphasizes that the body schema is subject to a process of sedimentation, during which certain bodily habits develop and become part of our style of being-in-the-world. ${ }^{6}$ This process is made apparent in neuropsychological conditions such as the phantom limb syndrome (occurring when people who undergo limb amputation retain awareness of the missing limb). Merleau-Ponty explains this phenomenon as the 
Forthcoming in J.E. Hackett \& J.A. Simmons (Eds.) (2016), Phenomenology for the Twenty-First Century. Palgrave Macmillan.

sedimentation of a certain habitual awareness of ourselves and of our relation to the world. When a limb is amputated, this habitual awareness does not suddenly change; the amputee retains a certain way of relating to the world and of knowing the world through her body.

The notion of sedimentation is closely related to the one of incorporation, in its most general sense. Incorporation is the acquisition, through a gradual process of sedimentation, of bodily habits and skills that, as such, are enacted spontaneously, without reflection. When one has acquired the capacity to walk down the stairs, for example, one does so spontaneously, without attending to one's legs or feet, and without thinking how to move each of them in turn. The body schema has taken into itself (incorporated) the ability to walk down the stairs, and just puts this ability into practice when needed. This is likewise the case for more complex skills that we might acquire later in life, such as dancing the waltz or climbing grade $7 \mathrm{~b}$ (these are my examples). Although complex activities are rarely if ever performed entirely "automatically", and always arguably involve a degree of conscious monitoring, they still necessarily depend on having acquired bodily habits that are then recruited during the activity (e.g., climbing grade $7 \mathrm{~b}$ requires the ability to perform moves such as feet swapping, crimping, and flagging). Merleau-Ponty emphasizes that the incorporation of bodily habits is never a matter of acquiring customs or routines involving mechanical and inflexible responses to stimuli. Rather the habitual body always retains a degree of adaptivity, spontaneity and freedom. Thus, once we have acquired the capacity to walk down the stairs, we can walk down stairs of different degrees of steepness and with differently-sized steps (for example).

I call this general sense of incorporation habit-incorporation, to distinguish it from a more specific use that Merleau-Ponty makes of the same term. This more specific use refers to the integration of material objects into the body schema, and I thus call it objectincorporation. Merleau-Ponty introduces the phenomenon with the following examples: 
Forthcoming in J.E. Hackett \& J.A. Simmons (Eds.) (2016), Phenomenology for the Twenty-First Century. Palgrave Macmillan.

Without any explicit calculation, a woman maintains a safe distance between the feather in her hat and objects that might damage it; she senses where the feather is, just as we sense where our hand is. If I possess the habit of driving a car, then I enter into a lane and see that 'I can pass' without comparing the width of the lane to that of the fender, just as I go through a door without comparing the width of the door to that of my body. ${ }^{7}$ Just like the body schema, the hat and the car in these examples are not objects of experience, but rather that which enables a certain experience of the world: 'The hat and the automobile have ceased to be objects whose size and volume would be determined through a comparison with other objects. They have become voluminous powers. ${ }^{, 8}$ Similarly,

The blind man's cane has ceased to be an object for him, it is no longer perceived for itself; rather, the cane's furthest point is transformed into a sensitive zone, it increases the scope and the radius of the act of touching and has become analogous to a gaze. ${ }^{9}$ Object-incorporation can be seen as a special form of habit-incorporation; it refers to cases in which our body schema has acquired specific habits by integrating material objects into itself. As others have noted already, ${ }^{10}$ the phenomenon of object-incorporation finds support in recent empirical evidence suggesting that tool use changes the way in which the brain responds to stimuli. We know for example that some neurons in the intraparietal cortex of Japanese macaques respond to visual stimuli applied at the hand, as well as near the hand. Once the macaque learns to pull food closer by using a rake, some of these neurons also respond when visual stimuli are presented near the rake. In the case of humans (where singleneuron recording is not possible), experimenters have found that wielding tools in a crossed position generates behavioral effects similar to those shown when the hands themselves are crossed. For example, judgments of the temporal order of vibrations applied to the far tip of crossed hand-held sticks are disrupted to a similar degree to when the vibrations are applied to crossed hands. ${ }^{11}$ 
Forthcoming in J.E. Hackett \& J.A. Simmons (Eds.) (2016), Phenomenology for the Twenty-First Century. Palgrave Macmillan.

The phenomenon of object-incorporation has also been discussed and elaborated in the field now known as 'postphenomenology.' This term, originally proposed by the philosopher of technology Don Ihde, refers broadly to the application of phenomenological methods and descriptions to the examination of our relations to technological artifacts. ${ }^{12}$ Drawing on Merleau-Ponty (as well as Husserl and Heidegger), Ihde has described how technologies mediate our experience, by modifying how we are intentionally related to the world. ${ }^{13}$ In particular, his notion of embodiment relations corresponds to what I have called 'objectincorporation.' In embodiment relations, artifacts are not thematized. When I write on a blackboard using a piece of chalk, for example, the chalk is not the intentional object of my awareness - it is not the 'terminus' of my experience. ${ }^{14}$ Instead, the piece of chalk is experienced as that through which the blackboard is given to me in the way it does (e.g., as hard and smooth). Ihde also points out that in embodiment relations artifacts are characterized by transparency or quasi-transparency — namely, they are not the main focus of attention but they 'withdraw' from experience, partially if not entirely. Ihde captures this relation formally with the following notation:

(human-artefact) $\rightarrow$ world

This notation indicates that the artifact is not itself the object of the intentional relation. Rather, the artifact is part of that which does the intending.

\section{Affective Habit-incorporation}

The preceding accounts describe incorporation (of some ability or object) within the sensorimotor body, i.e., the perceiving and moving body. In the remaining of this chapter I suggest that it is possible to talk of incorporation also in the affective domain, both in the 
Forthcoming in J.E. Hackett \& J.A. Simmons (Eds.) (2016), Phenomenology for the Twenty-First Century. Palgrave Macmillan.

general sense of habit-incorporation (this section), and in the more specific sense of objectincorporation (next section).

Before proceeding, I need to clarify what I mean by 'affectivity.' I use the term in a general way, to refer to the capacity as well as the condition of being affected (literally, 'done something') by something. Being affective, in this general sense, is incompatible with being indifferent, deprived of any interest, concern, or care for one's existence and/or world. Paradigmatic affective states_-states that most clearly display this lack of indifference — are emotions (happiness, sadness, fear, anger, guilty, shame, etc.), moods (feeling up or down, being cranky, grumpy, having the blues, etc.), and motivational states (fatigue, hunger, pain, etc.). Although there is no agreement among affective theorists on how to define these states, I think it is fair to say that it is not controversial to classify them all as 'affective.'

Accordingly, in the rest of this chapter I discuss the possibility of incorporating skills and objects into affective states conceived in this broad way. ${ }^{15}$

Let us then consider, first, whether and how affective habits and skills can be incorporated. This case is fairly straightforward. Just think of the many bodily ways of expressing specific emotions that we acquire during our lifetime. We know from empirical research that some facial expressions of emotions appear very early in development. ${ }^{16}$ Yet as life progresses we acquire a repertoire of further facial expressions, as well as vocalizations and bodily gestures, that are dependent on our environment and culture. Cross-cultural studies of emotion expression have focused primarily on identifying pancultural facial expressions ${ }^{17}$; yet whoever has travelled in different countries will have noted that there are cultural variations in the way emotions are expressed in the face and rest of the body. Just to give an example from my own experience, in my country of origin (Italy), but not in the country I live (the UK), spreading the arms and slightly tilting the neck backwards and sideways expresses a form of exasperation (a typical vocalization and facial expression usually accompany the 
Forthcoming in J.E. Hackett \& J.A. Simmons (Eds.) (2016), Phenomenology for the Twenty-First Century. Palgrave Macmillan.

gesture as well). ${ }^{18}$ We can talk here of the sedimentation of a certain affective style, ${ }^{19}$ or the incorporation of an affective communicative gesture into one's habitual body. As was the case for Merleau-Ponty's sensorimotor skills (such as walking down the stairs), this bodily habit exhibits regularity and flexibility at the same time. It is 'activated' in certain contexts, but it is not just a reflex or conditioned response; I modulate it depending on whom I talk to- - e.g., I might perform a more restrained version of the gesture in a relatively formal setting, and a more exaggerated version in an informal setting, especially one that invites emphasizing one's origins (when I interact with other Italians abroad, performing this and other culture-specific attitudes is sometimes a way of bodily-making the point, by exhibiting and sharing a gesture that is mutually understood, that we are now 'between us'). At the same time, the habit remains spontaneous; I do not first think 'now I will act exasperated' and then perform the gesture, rather I experience the social context as inviting or affording that gesture (in a restrained or exaggerated way), and I accordingly 'go with it,' in a continuous stream of experience and action where there is no moment of 'deciding' distinct from and preceding the moment of 'doing.' Likewise, with the same spontaneity and lack of antecedent reflection, I do not perform that gesture when I interact with British people, because I usually do not experience those interactions as inviting that kind of behavior.

Incorporating an affective style in the sense just specified is, importantly, not only a matter of acquiring a way of performing a gesture but also of undergoing an affective experience while doing so. Indeed that is what warrants talking of an affective style in the first place. Performing the gesture of exasperation mentioned above comes with a specific feeling that is at the same time an affective feeling and a feeling of how the body is moving - indeed the two are not distinct, rather the way my body feels as I spread my arms and tilt my neck is part of how it feels to act exasperated. The point of these considerations is that affective habitincorporation is not just a matter of taking into the body a certain way of outwardly 
Forthcoming in J.E. Hackett \& J.A. Simmons (Eds.) (2016), Phenomenology for the Twenty-First Century. Palgrave Macmillan.

expressing some emotion (for example), but also a matter of inwardly acquiring a bodilyaffective way of feeling. The acquisition of an affective style affects both how our body appears to others, as well as how it is experienced in the first person.

Much more could be said about the incorporation of affective habits. For one, not only emotions but also moods and arguably motivational states come with characteristic bodily attitudes and experiences that appear to change and sediment over time. Indeed, the development of one's personality can be seen as including a process of affective incorporation, in the sense of the gradual acquisition of several dispositions to respond affectively in specific ways. And there is also the interesting phenomenon of how professional performers, such as actors and dancers, come to incorporate a variety of affective styles in their repertoire. The aim of this chapter, however, is only to begin sketching the phenomenon of affective incorporation, and to this end I now move on to the other, more specific sense of incorporation identified earlier: the one of object-incorporation.

\section{Affective Object-incorporation}

I now propose that it is possible to talk of the integration of material objects into bodilyaffective episodes. This phenomenon is less obvious than the one of affective habitincorporation. To introduce it and characterize it in some detail, in this section I offer two examples.

\section{Example One: The Hikers}

Central to the first example is the consideration that affectivity is not just a state of the body (a pattern of changes in the physiological body and/or in bodily feelings), but a way in which the world, or parts of it, are given or 'show up' in experience for the subject. Consider, for instance, how the world shows up in moods, which are often characterized as affective states 
Forthcoming in J.E. Hackett \& J.A. Simmons (Eds.) (2016), Phenomenology for the Twenty-First Century. Palgrave Macmillan.

that are not intentionally directed at anything in particular. ${ }^{20}$ In spite of this lack of specificity of the intentional object, arguably moods remain 'open' to the world, in the sense that they involve a reference to something 'other.' Different moods change the affective character of the world, i.e., how the world affects or strikes the subject. Using a term influential in psychology in the 1930 s, ${ }^{21}$ we can say that different moods change the 'invitation' or 'demand' character of the world, namely, the extent to which the world is experienced as repelling or attracting. ${ }^{22}$ In a downward or depressed mood the world appears flat and invites little or no interaction, whereas in an energized mood, the world appears more inviting and enticing. There is no reason why this kind of analysis could not be applied to other affective episodes too, such as emotional and motivational ones. Unlike moods, emotional episodes are typically regarded as being about specific objects, events, or situations. Phenomenologically, we may say that emotion experiences are more focused, and whereas it is not 'the world in general' that affects or strikes the subject in a specific way during an emotional episode, we can still talk of parts of the world that show up in specific ways during an emotion, notably as inviting certain actions and deterring others. Thus in fear, the feared object may invite moving away from it; in anger, parts of the world may invite hitting and punching; in attraction, they may invite touching and kissing, and so on. ${ }^{23}$ Likewise for motivational states such as hunger, thirst, or pain. These states involve clear felt tendencies or urges toward or away from something, and correlatively influence how parts of the world are experienced. ${ }^{24}$

Importantly for present purposes, the ways in which the world is given in experience in all these affective states depend in a constitutive way on one's bodily self-awareness, such as awareness of the possibilities of action that are available to one's own body-or so I want to suggest. Consider for example how differently a steep ascending flight of stairs shows up for you depending on whether you are fatigued or energized. When you are fatigued, it looks daunting and uninviting; this look, I claim, depends on the experience you have of your body 
Forthcoming in J.E. Hackett \& J.A. Simmons (Eds.) (2016), Phenomenology for the Twenty-First Century. Palgrave Macmillan.

as fatigued and thus unable, or only able with significant effort, to climb up the stairs. On the other hand, when you are energized — perhaps you are out for a run and you feel full of strength — the stairs do not look so daunting, they might even look inviting and stimulating; again, it is the awareness you have of your body as strong, energized and 'ready to go' that makes the stairs show up in experience in this way. In recent work, I have suggested the metaphor of looking at the world through a colored but still transparent window to capture this idea that it is through a certain experience of one's own body (the colored window) that we experience the world as affecting us in one way or the other. ${ }^{25}$

We can trace the idea that the affective character of the world depends constitutively on the character of the lived body in Merleau-Ponty's discussion of sexuality, which he regarded as falling squarely within the 'affective milieu. ${ }^{, 26}$ Merleau-Ponty argues that the sexual body (characterized as Freudian Eros or Libido) is what constitutes the world as erotic, as offering sexual possibilities; it 'gives external stimuli a sexual value or signification. ${ }^{, 27}$ Erotic 'comprehension' is not intellectual understanding, but 'the power of projecting before [oneself] a sexual world. ${ }^{28}$ Patients who suffer from sexual inertia, who are not able to act upon their sexual desires and to follow through a sexual act, correlatively lack 'sexual intentionality,' they fail to project or constitute people as erotic and as inviting sexual interactions. $^{29}$

We are now in a position to introduce one way in which material objects can be incorporated into affective episodes. Consider the following example. Stevie and Frankie are two hikers with the same level of expertise, health, and fitness. They are at the top of a mountain, at the beginning of a steep downhill path covered with small stones and gravel. Stevie is wearing sturdy hiking boots, whereas Frankie is wearing light tennis shoes with a flat sole. As they begin walking down and feeling the terrain with their feet, Stevie feels confident and safe, whereas Frankie feels unsecure and afraid. As Frankie puts her feet down, 
Forthcoming in J.E. Hackett \& J.A. Simmons (Eds.) (2016), Phenomenology for the Twenty-First Century. Palgrave Macmillan.

she feels she can easily slip, and the path shows up for her as treacherous and dangerous.

Stevie on the other hand feels he can walk down confidently, securely placing his feet on the ground, and the path appears safe and walkable to him. None of them, I contend, are attending to their shoes as they walk down (at least, this seems to me what happens when one climbs down a steep mountain path). Nor, however, are the shoes entirely absent from the hikers' awareness. Rather, it seems appropriate to characterize the shoes as quasi-transparent, i.e., as 'withdrawn' from experience (not attended, not taken as an intentional object) but still present in it as that through which the path shows up for the hikers in the way it does. Specifically, wearing sturdy boots compared to light flat shoes alters the implicit sense of one's possibilities of action in relation to the path. Borrowing a term from ecological psychology, we can say that wearing different shoes changes awareness of one's effectivities - the set of motor skills that one possesses and that correlate with awareness of what actions the world invites or affords. ${ }^{30}$ In sum, I suggest that we have here a case where two different affective worlds are 'projected' by two subjects through the integration of different material objects into their body schema. The structure of this example is the same as the one of cases of object-incorporation in the sensorimotor domain, namely: (human-artifact) $\rightarrow$ world.

Before considering another example, let me reply to a possible objection or perplexity. One could argue that the example just given is one in which the shoes are incorporated into the hikers' perceptual (tactile) experience of the path, but not in their emotional state; the latter is simply a feeling (of fear, or of confidence) caused by the hikers' different perception of the qualities of the path. The problem with this account, in my view, is that it artificially isolates the perceptual component of the experience from the affective one, leaving the latter dangling, unanalyzed, at the end of a causal sequence of psychological states. As such, this account is not a description of affective experience. But such a description is precisely what I am after. In particular I aimed to provide a phenomenologically appropriate characterization 
Forthcoming in J.E. Hackett \& J.A. Simmons (Eds.) (2016), Phenomenology for the Twenty-First Century. Palgrave Macmillan.

of the affective experience of the hikers, and of how their body, the shoes and the path feature in it. To retort that the affective experience is a mere feeling that comes after the perception of the path (as either slippery or not) fails to take into account that affective feelings maintain a connection to the world by influencing how the world is given in experience.

Likewise, redescribing the example of the hikers as one where two different emotions are caused by a cognitive evaluation (or appraisal) of the situation would not provide a satisfactory account of the experience of those emotions. Suppose one said that Frankie judges that it is dangerous to walk down with light flat shoes, and accordingly becomes worried or scared. Again, this account says nothing about Frankie's actual experience of worry or fear. It leaves this experience dangling at the end of a causal sequence of nonaffective psychological processes (a perception, leading to an appraisal, leading to a feeling), and provides no description of how the body and the world feature in it.

\section{Example Two: The Instrumental Musician}

Consider next the example of a professional instrumental musician, who sets out to play to regulate her affective state-e.g., she would like to calm down, or to feel more motivated and energized, or might want to 'vent' or give voice to a specific affective state, such as sadness or longing. For present purposes it does not matter whether or not the musician already feels something specific before playing, and whether and how playing changes this initial feeling. All that the example requires is that the musician engages in the activity of playing in order to influence (change, amplify, dampen, etc.) what she is feeling (including feeling nothing in

particular). ${ }^{31}$ Also, we can imagine that the musician either improvises, or plays a piece composed by someone else. I am not a professional musician but I certainly sometimes play the piano to regulate my affective state. And apparently professional musicians do this too. Here is, for example, what the pianist Cristina Ortiz said of her relation to the piano: 
Somebody took a piano from me, it would be my death, because I live through the piano. Whatever happens in my life - depression, pressure, happiness, or the loss of mother or father ...-I go to the piano, and my soul comes through [the] pieces I choose to portray that emotion. ${ }^{32}$

The question of how affect and music relate to each other is notoriously a difficult and muchdebated one (there is a whole Handbook dedicated to the topic ${ }^{33}$ ). We know from empirical research that music influences the listener's affective state. ${ }^{34}$ One way in which playing an instrument affects the performer's affective state is thus in virtue of the performer hearing the music he plays. Yet aside from this empirical fact it is hard to characterize the nature of the music-induced affective state. In particular, what is it about? Is it about anything at all? Is it about the music, about affect itself, about both, or about something else? For present purposes we can leave aside these complex philosophical questions, ${ }^{35}$ and focus instead on the musician's first-personal experience of playing an instrument and of being affected in the act of playing — not just by the quality of the music he plays, but more generally by the act of engaging in a music-producing performance.

The question of interest here, then, is: how does the musician experience the instrument while playing? My suggestion is that the instrument is experienced as that through which a certain affective state is realized, created, or even better 'articulated' in the performance. In this process, the instrument is not taken as an intentional object, but neither is it incorporated only into the musician's sensorimotor schema. Undoubtedly, the skilled pianist does not pay attention to how distant the next key is from the one she is currently pressing, or to the location of the pedals; her body has incorporated a complex set of sensorimotor skills so that she can pre-reflectively reach for various parts of the instrument without having to focus on them. And yet, a musical performance is not just a sensorimotor activity; accordingly, I want to suggest, the instrument is not incorporated only into the sensorimotor 
Forthcoming in J.E. Hackett \& J.A. Simmons (Eds.) (2016), Phenomenology for the Twenty-First Century. Palgrave Macmillan.

schema. While performing (in the context delineated in the example), the musician is affectively touched by what she plays, and she is also motivated to play in a certain affective way (a way that will strike her as so or so). We can say that the musician's body has not just a motor intentionality, but an affective intentionality as well. ${ }^{36}$ As the musician plays, she is striving to create, or articulate, a certain affective state. By 'articulating' an affective state I mean supporting how it unfolds in real time, by being receptive to it from moment to moment, and by sustaining it with what and how one plays next. During this process of affective articulation, the musician experiences her body in complex ways: the lived body may alternate between being very much 'at the front' and conspicuous in awareness, and being inconspicuous and in the background. ${ }^{37}$ It is unlikely that the instrument will be experienced in the same complex way. After all, unlike the body, the instrument is not traversed by a nervous system and thus cannot be the source of proprioceptive and kinesthetic sensations. So one cannot feel 'shivers down the instrument,' for instance, like one feels shivers down the spine. Likewise, whereas one can feel one's own body as being the locus of a motor intention or urge to act, it does not seem possible to feel the instrument in this way. And yet, I suggest, there is a sense in which the instrument is experienced as the body isnamely as that which makes the articulation and creation of an affective state possible. The instrument, like the body, is experienced as that through which the musician can let herself 'go through' a certain affective process.

One may retort at this point that this example does not fit the structure '(humanartifact) $\rightarrow$ world' because the complex '(human-instrument)', unlike instances of sensory perception, does not intend a specific aspect of the world. As mentioned earlier, it is indeed difficult to say what music is about; in addition, it is difficult to say what the musician's affective state while playing is about. One possibility might be that the musician's affective state is a mood that, as such, is not about anything in particular. I do not think this is the case, 
Forthcoming in J.E. Hackett \& J.A. Simmons (Eds.) (2016), Phenomenology for the Twenty-First Century. Palgrave Macmillan.

however, because when one is playing one's experience can be (and mostly is, I would say) directed at quite specific objects, such as the music one is playing, and (at least in the example given in this section) at how the music is affecting one. So I think that what makes it hard to see how the example fits the structure '(human-artifact) $\rightarrow$ world' is the complexity of the intentional object of the experience. This difficulty, however, does not pertain to the 'intending' side of the formula, namely to '(human-artifact) $\rightarrow \ldots$..' What I argued above is that in the given example the instrument is not the intentional object of the experience (i.e., it is not the case that 'human $\rightarrow$ instrument'), but should be regarded as incorporated into the activity of intending something. The fact that this something is difficult to characterize and may be shifting does not affect the incorporated status of the instrument.

\section{Conclusion}

In this chapter I aimed to delineate some of the ways in which the affective body can incorporate something else- - from habits and skills, to material objects. I did so by building upon existing discussions of incorporation in the sensorimotor domain, specifically by Merleau-Ponty and Ihde.

Much more remains to be said about the phenomenon of affective incorporation, both in the sense of acquisition of bodily-affective habits and skills, and in the sense of integration of material objects into the affective body. This is because affectivity is a complex and multifaceted domain, and the body enters in it in various ways. For reasons of space, I have not said anything here about, for example, the incorporation of objects into the 'body image,' namely, into our conscious image of how our body appears to others. ${ }^{38}$ I have not discussed either the possibility of incorporating objects (such as drugs) into the physiological dimension of affectivity. Habits, skills and objects could also be incorporated into one's personality, and even into one's sense of self and personal identity. In spite of the preliminary nature of the 
Forthcoming in J.E. Hackett \& J.A. Simmons (Eds.) (2016), Phenomenology for the Twenty-First Century. Palgrave Macmillan.

present discussion, I hope to have demonstrated one way in which we can take classic phenomenological themes further into the Twenty-First century. ${ }^{39}$

\footnotetext{
Notes

${ }^{1}$ See, for example, D. Welton, ed.., The Body: Classic and Contemporary Readings (Malden, MA: John Wiley \& Sons, 1999).

${ }^{2}$ See, M. Merleau-Ponty, Phenomenology of Perception, trans. D. A. Landes (Abingdon and New York: Routledge, 1945/2012); D. Ihde, Technics and Praxis (Boston, MA: D. Reidel, 1979). I focus on these authors for reasons of space. Other phenomenologists, such as Heidegger and Sartre, have also provided relevant accounts of incorporation or closely related phenomena.

${ }^{3}$ Here and in the rest of the chapter I follow Landes's recent translation of Phenomenology of Perception.

${ }^{4}$ In other words, the body schema is a transcendental structure or process, along the lines of Kant's

"transcendental schema" (see T. Carman, Merleau-Ponty (London and New York: Routledge, 2008), pp. 105106). The latter refers to a procedure by which concepts are provided with images. So the transcendental schema is not itself an image in the sense of an object of awareness; rather it is that which enables and structures our awareness of objects. Merleau-Ponty's body schema is, similarly, a structure or process that enables our experience of objects.

${ }^{5}$ Merleau-Ponty, Phenomenology of Perception, p. 103.

${ }^{6}$ The geological metaphor of sedimentation comes from Husserl, where it refers to the gradual establishment of patterns of understanding and expectations in the history of knowledge. See E. Husserl, The Crisis of European Sciences and Transcendental Phenomenology, trans. D. Carr (Evanston: Northwestern University Press, 1954/1970). For a useful discussion of the habitual body in Merleau-Ponty and its relation to Bergson's notion of "habit memory," see also E.S. Casey, 'Habitual Body and Memory in Merleau-Ponty,' Man and World, 17, no. 3-4 (1984): pp. 279-97.

${ }^{7}$ Merleau-Ponty, Phenomenology of Perception, p. 144.

${ }^{8}$ Merleau-Ponty, Phenomenology of Perception, p. 144.

${ }^{9}$ Merleau-Ponty, Phenomenology of Perception, p. 144.

${ }^{10}$ For example, see S. Gallagher, How the Body Shapes the Mind (Oxford: Oxford University Press, 2005), p.

32; H. De Preester, 'Technology and the Body: the (Im)Possibilities of Re-embodiment,' Foundations of Science 16, no. 2-3 (2011): pp. 119-37.

${ }^{11}$ For these and related findings, see A. Maravita and A. Iriki, 'Tools for the Body (Schema),' Trends in Cognitive Sciences 8, no. 2 (2004): pp. 79-86; L. Cardinali, F. Frassinetti, C. Brozzoli, C. Urquizar, A.C. Roy, and A. Farnè, 'Tool-use Induces Morphological Updating of the Body Schema,' Current Biology 19 (2009), R478-R479; A. Sposito, N. Bolognini, G. Vallar, and A. Maravita, 'Extension of Perceived Arm Length Following Tool-use: Clues to Plasticity of Body Metrics,' Neuropsychologia 50 (2012): pp. 2187-94; G. Ganesh, T. Yoshioka, R. Osu, and T. Ikegami, T., 'Immediate Tool Incorporation Processes Determine Human Motor Planning with Tools,' Nature Communications 5 (2014).

${ }^{12}$ Unlike other intellectual movements that criticize approaches of which they are 'post' (e.g., posthumanism, postmodernism), postphenomenology is thus rather a continuation of classic phenomenology. For a discussion of the relation between phenomenology and postphenomenology, see H. De Preester, 'Postphenomenology, Embodiment and Technics: Don Ihde, Postphenomenology and Technoscience: The Peking University Lectures,' Human Studies 33, no. 2-3 (2010): pp. 339-45.

${ }^{13}$ For example, see D. Ihde, Technics and Praxis; see also, D. Ihde, Postphenomenology and Technoscience: The Peking University Lectures (Albany: State University of New York Press, 2009).

${ }^{14}$ Ihde, Technics and Praxis, p. 7.

${ }^{15}$ In The Feeling Body, I argued that affectivity pervades the whole mind, and thus that cognitive states as well are affective. For the purposes of this chapter however I only focus on those states that are more commonly viewed as affective. See G. Colombetti, The Feeling Body: Affective Science Meets the Enactive Mind (Cambridge, MA: MIT Press, 2014).

${ }^{16}$ See, for example, M.W. Sullivan and M. Lewis, M., 'Emotional Expressions of Young Infants and Children: A Practitioner's Primer,' Infants \& Young Children 16, no. 2 (2003): pp. 120-42; T. Chaplin and A. Aidao, 'Gender Differences in Emotion Expression in Children: A Meta-analytic Review,' Psychological Bulletin 139, no. 4 (2013): pp. 735-65.
} 
Forthcoming in J.E. Hackett \& J.A. Simmons (Eds.) (2016), Phenomenology for the Twenty-First Century. Palgrave Macmillan.

${ }^{17}$ See D. Matsumoto and H.S. Hwang, 'Facial Expressions,' In Nonverbal Communication: Science and Applications, eds. D. Matsumoto, M.G. Frank, H.S. Hwang (Thousand Oaks, CA: Sage, 2013), pp. 15-52.

${ }^{18}$ For an extensive (if somewhat outdated) guide to gestures across different cultures, see also D. Morris, Bodytalk: A World Guide to Gestures (London: Jonathan Cape Ltd, 1994).

${ }^{19}$ I owe the notion of 'affective style' to Joel Krueger (see G. Colombetti and J. Krueger, 'Scaffoldings of the Affective Mind,' Philosophical Psychology, 28, no. 8 (2015): pp. 1157-1176. This notion is related to the one of 'somatic style' advanced by Shusterman, although he does not explicitly discusses affectivity and emotions, and rather focuses on various sensory dimensions of personal style (visual, sonic, tactile, etc.) (R. Shusterman, 'Somatic Style,' The Journal of Aesthetics and Art Criticism 69, no. 2 (2011): pp. 147-59). For a relevant analysis of the notion of style, habit and institution in Husserl, see D. Meacham, 'What Goes Without Saying: Husserl's Concept of Style,' Research in Phenomenology 43, no.1 (2013): pp. 3-26.

${ }^{20}$ For example, P. Goldie, The Emotions: A Philosophical Exploration (Oxford: Oxford University Press., 2000).

${ }^{21}$ See, for example, K. Koffka, Principles of Gestalt Psychology (London: Routledge and Kegan Paul, 1935); K. Lewin, A Dynamic Theory of Personality: Selected Papers, trans. D. K. Adams and K. E. Zener (New York: McGraw-Hill, 1935).

${ }^{22}$ The term used by Lewin in the original German text was Aufforderungscharakter (from auffordern, to stimulate, to solicit). Interestingly, this term was translated into English as 'valence.' The latter is now a major construct in affective science, where it refers to the positive and negative character of emotions (G. Colombetti, 'Appraising Valence,' Journal of Consciousness Studies 12, no. 8-10 (2005): pp. 103-26). The notion of 'invitation character' influenced Merleau-Ponty himself, and later also Gibson's theory of affordances (J. J. Gibson, The Ecological Approach to Visual Perception (Boston, MA: Houghton, Mifflin and Company, 1979)). For a discussion of affordances and the 'affective allure' of the world, see also E. Rietveld, 'Situated Normativity: The Normative Aspect of Embodied Cognition in Unreflective Action,' Mind 117, no. 468 (2008): pp. 973-1001.

${ }^{23}$ For the view that emotion experiences involve urges to act or 'action tendencies,' see also N.H. Frijda, The Emotions (Cambridge: Cambridge University Press, 1986).

${ }^{24}$ The distinction between emotions, moods, and motivational states should not be seen as set in stone. Emotional states, and arguably moods too, are themselves motivating, for example. The distinction is primarily meant to characterize different features of the affective domain, not to divide it into non-overlapping categories. ${ }^{25}$ G. Colombetti, The Feeling Body; and 'Varieties of Pre-Reflective Self-Awareness: Foreground and Background Bodily Feelings in Emotion Experience,' Inquiry 54, no. 3 (2011): pp. 293-313.

${ }^{26}$ Merleau-Ponty, Phenomenology of Perception, p. 156. The Phenomenology of Perception otherwise offers only some sparse considerations about affectivity and emotions. For an elaboration of Merleau-Ponty's views on the topic, see K. Romdenh-Romluc, Routledge Philosophy GuideBook to Merleau-Ponty and Phenomenology of Perception (New Ed) (Oxon and New York: Routledge, 2011), pp. 183-94.

${ }^{27}$ Merleau-Ponty, Phenomenology of Perception, p. 158.

${ }^{28}$ Merleau-Ponty, Phenomenology of Perception, p. 158.

${ }^{29}$ Merleau-Ponty, Phenomenology of Perception, pp. 157-60.

${ }^{30}$ The notion of 'effectivities' was introduced by Turvey and colleagues to refer to properties of the animal to which affordances are relative (R. Shaw, M.T. Turvey, and W. Mace, W., 'Ecological Psychology: The Consequence of a Commitment to Realism,' in Cognition and the Symbolic Processes vol 2, eds. W. Weimer and D. Palermo (Hillsdale, NJ: Lawrence Erlbaum Associates, Inc, 1982), pp. 159-226). Again, I am using this notion to refer to the experience of one's possibilities of action in the world.

${ }^{31}$ I am intentionally avoiding saying that the musician 'expresses' some emotion while playing, because expression is a multi-faceted phenomenon that can refer to both how an audience perceives a performance, and to the subjective experience of expressing. The example of the self-regulating musician does not require her to play expressively (however ones interprets this term).

32 BBC Radio 3. (Producer). (2012). Personal connections with the piano-Leeds International Piano Competition 2012. [Video webcast]. Available from http://www.youtube.com/watch?v1/4HQurNBRu9m4\&list 1/4 PL2kzIPyOVx7BCXM_rG_zy1HQPQEIVDIV8

${ }^{33}$ P.N. Juslin and J. A. Sloboda, ed. Handbook of Music and Emotion: Theory, Research, Applications (Oxford: Oxford University Press, 2010).

${ }^{34}$ See, for example, P.N. Juslin, S. Liljeström, D. Västfjäll, and L.O. Lundqvist, 'How does music evoke emotions? Exploring the underlying mechanisms,' in Handbook of Music and Emotion, eds. Juslin and Sloboda, pp. 605-43.

${ }^{35}$ For overview and references, see A. Kania, 'The Philosophy of Music,' Stanford Encyclopedia of Philosophy, ed. E. N. Zalta 2007. 
Forthcoming in J.E. Hackett \& J.A. Simmons (Eds.) (2016), Phenomenology for the Twenty-First Century. Palgrave Macmillan.

\footnotetext{
${ }^{36}$ We find a similar, albeit undeveloped, observation in Merleau-Ponty. He writes of an organist rehearsing a piece that his gestures 'put forth affective vectors, they discover emotional sources' (Phenomenology of Perception, p. 147).

${ }^{37}$ Colombetti, The Feeling Body, pp. 128-32.

${ }^{38}$ For some preliminary considerations, see Colombetti and Krueger, 'Scaffoldings of the Affective Mind.'

${ }^{39}$ Many thanks to Tom Roberts, Adam Toon, Aaron Simmons, and audiences in Prague, Pilsen and Sheffield for comments on earlier versions of this chapter.
} 